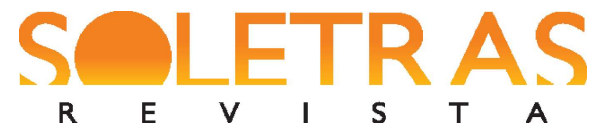

\section{A construção de atenuação do discurso com verbo suporte trazer: uma abordagem construcional baseada no uso}

Fábio Rodrigo Gomes da Costa ${ }^{1}$ Marcia dos Santos Machado Vieira ${ }^{2}$

Resumo: O presente artigo tem como objetivo analisar a construção de atenuação do discurso, que, no plano da forma, é representada pela estrutura [trazer $\underline{\underline{V}}_{\text {suporte }}+$ Elemento não-verbal predicante (com Ndeverbal)] predicador verbal complexo. Esta construção licencia subesquemas construcionais que ou envolvem SN com Ndeverbal ou SP com Ndeverbal no segundo slot, destinado a elemento não-verbal predicante. A construção e seus subesquemas construcionais estão interconectados em uma rede construcional por meio de links taxonômicos, horizontais, sintáticos e lexicais, conforme o modelo de rede proposto por Diessel (2015). As expressões observadas, coletadas no banco de dados do site eletrônico da Assembleia Legislativa do Rio de Janeiro (ALERJ), foram identificadas em discursos de deputados entre os anos de 2011 e 2019. O aparato teórico-metodológico desta análise é a Linguística FuncionalCognitiva e da Gramática de Construções Baseada no Uso (GCBU). Da análise de dados, destacam-se estes resultados: (i) o preenchimento de elemento não-verbal por SN com Ndeverbal viabiliza moldar o participante sujeito (que pode coincidir ou não com o enunciador) na figura de um porta-voz e (ii) seu preenchimento por SP com Ndeverbal viabiliza sobressair o papel do interlocutor no estado de coisas encaminhado pelo enunciador.

Palavras-chave: Construção com verbo suporte; Atenuação do discurso; Gramática de Construções Baseada no Uso; Linguística Funcional-Cognitiva.

\title{
Introdução
}

O propósito da pesquisa aqui exposta é realizar uma análise de dados oriundos de padrões construcionais licenciados por [Trazer vsuporte

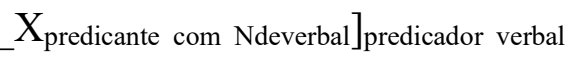

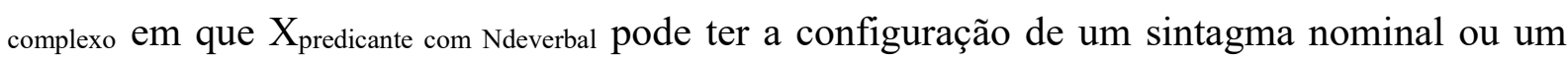
sintagma preposicional. Em ambos os casos, esse sintagma liga-se ao verbo trazer com o qual forma uma unidade verbal que funciona à semelhança de um predicador verbal simples em predicações verbais. Padrões construcionais licenciados por essa construção de predicador

\footnotetext{
${ }^{1}$ Doutorando em Língua Portuguesa no Programa de Pós-Graduação em Letras Vernáculas da Universidade Federal do Rio de Janeiro (UFRJ). Membro do grupo de pesquisa Predicar: Formação e expressão de predicados complexos e predicações. E-mail: fabiorodrigogc@yahoo.com.br. ORCID iD: 0000-0003-1831-2443

${ }^{2}$ Doutora em Letras Vernáculas, Universidade Federal do Rio de Janeiro. Professora do Programa de PósGraduação em Letras Vernáculas da UFRJ. É líder do grupo de pesquisa registrado no diretório de grupos do CNPq Predicar: Formação e expressão de predicados complexos e predicações. E-mail: marcia@letras.ufrj.br. ORCID iD: 0000-0002-2320-5055
} 


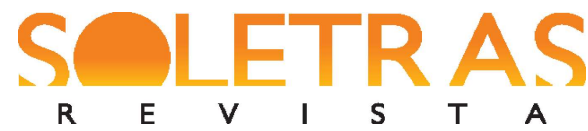

N. 41 - 2021.1 - FÁBIO RODRIGO GOMES DA COSTA

MARCIA DOS SANTOS MACHADO VIEIRA

verbal complexo funcionam como atenuadores do discurso. A construção aqui focalizada é captada na representação mais esquemática: [Trazer $\underline{\text { vsuporte }}^{+}$ Elemento não-verbal predicante (com Ndeverbal)] predicador complexo de atenuação do discurso. Ao observarmos os discursos de deputados na Assembleia Legislativa do Rio de Janeiro (ALERJ), identificamos a recorrência de instanciações dessa construção segundo alguns padrões construcionais, conforme mostraremos a seguir:

a) "Eu gostaria, porém, de também trazer minha opinião. Assim como respeito a opinião de alguns colegas, quero dizer que sou contra a lei de criminalização da homofobia. Não sou contra o homossexual, contra as lésbicas, acho que cada um escolhe sua vida, seu destino. Mas nós precisamos respeitar os que discordam. Acho que temos que ter um discurso respeitoso.” (ALERJ, 12/ 05/2011)

b) "Sra. Presidente, Sras. e Srs. Deputados, servidores da Assembleia Legislativa do Estado do Rio de Janeiro, quero aproveitar o meu tempo nesta tribuna hoje para tratar de alguns assuntos importantes que temos observado ao longo desses meses, com relação ao governo do Estado. Quero também aproveitar o momento para trazer algumas explicacões, diante das falas de alguns Deputados que aqui vieram com o intuito de criticar sem trazer uma solucão e de estender o tempo da fala para que a Sessão acabasse e não votássemos o projeto do governo no dia de hoje. Para não cair nessa estratégia da oposição, preferi aguardar o meu tempo no Expediente Final.” (ALERJ, 03/12/2019)

c) "Sr. Presidente, Deputadas e Deputados presentes nesta Sessão. Importante tomar lugar neste plenário, trazer à discussão temas que são importantíssimos, mas que possamos fazer desse lugar, que é do parla, do parlamento, um lugar de fato pedagógico e que aí façamos citações de fato com os autores das citações." (ALERJ, 06/08/2019)

d) "Sr. Presidente, Deputado Roberto Henriques, Sras. e Srs. Deputados, ao retomarmos as atividades de Plenário, quero, cumprimentando os colegas parlamentares, trazer de volta um tema que aqui abordamos na última Sessão." (ALERJ, 02/08/2011)

e) "Muito obrigado, Deputado Waldeck Carneiro, que preside essa parte do Expediente Final, Sras. e Srs. Deputados, eu gostaria de abrir aqui a minha participação para trazer ao conhecimento dos senhores e da Casa fatos ocorridos, hoje.

Estando eu ausente do plenário, no início dos debates desta tarde, fui informado que alguns Deputados se manifestaram sobre esse assunto, então, me julgo na responsabilidade de trazer aqui esclarecimentos aos Deputados, aos funcionários da Casa, e, evidentemente, à população carioca e fluminense." (ALERJ, 05 de abr. de 2018)

Ao observarmos os dados acima, podemos identificar que as expressões "trazer minha opinião", "trazer algumas explicações", "trazer uma solução", "trazer esclarecimentos", 
"trazer à discussão" e "trazer de volta" avizinham-se de certos predicadores simples, ou até são funcionalmente comparáveis a estes: opinar, explicar, solucionar, esclarecer, discutir e voltar. Enquanto nos predicadores complexos com verbo suporte trazer se explicita a relação de causação envolvida na predicação verbal e, por conseguinte, o papel de causador do participante sujeito, essas propriedades não são marcadas nos predicadores simples (quase) equivalentes.

Assumimos que os predicadores complexos com verbo suporte trazer configuram uma dinâmica de forças distinta da evocada pelos predicadores simples. Em ambas as expressões, o antagonista (ou o sujeito) é a entidade mais forte. No entanto, nas expressões com verbo suporte trazer, percebemos uma diminuição de sua energia volitiva devido à ação de movimento que conduz, inclusive, em direção à perspectivação de outro participante (o interlocutor e até um terceiro suposto participante na ação de opinar, explicar, solucionar, discutir, esclarecer). $\mathrm{O}$ acionamento do predicador complexo com trazer provoca a ativação de outra distribuição de forças: o encaminhamento da ação na cena enunciativa nesse movimento pode iluminar o movimento do causador ("trazer minha opinião") ou a relação entre sujeito causador-autor/enunciador e seu interlocutor (“trazer à discussão"), podendo, ainda, até sugerir o envolvimento de terceiro(s) na responsabilidade pela ação ("trazer esclarecimentos", até de outros); e, então, em alguma medida ou se subfocaliza o lugar agentivo do participante sujeito autor-causador ou, ainda, se lhe atribui um lugar de porta-voz. Essas possibilidades do nosso sistema conceptual de apresentar eventos de comunicação verbal como transferência ligam-se à alternância de perspectiva: um evento comunicativo pode ser conceptualizado de diferentes ângulos, entre os quais o da atenuação do participante sujeito. E esta manifesta-se, entre outros recursos linguísticos, pelo acionamento da construção aqui tratada.

A configuração de $\mathrm{N}_{\text {deverbal }}$ (singular ou plural) e de sua projeção em SN contendo ou não determinantes/quantificadores ou até modificadores sujeita-se a uma certa variabilidade (no que diz respeito à configuração sintagmática que se manifesta em cada construto) com potencial de afetar, em maior ou menor intensidade, a relação de associação, por similaridade, com predicadores verbais simples. Afinal, a partir de Machado Vieira (2010, 2018, entre outras referências), sabemos que a condição de Ndeverbal sem determinante ou modificador ou de Ndeverbal antecedido de determinante (em geral, artigo) que não colabore para o seu 
funcionamento referencial (por ser apenas classificatório do estado de coisas mais geral, "ação/causação" na construção em estudo) é um dos parâmetros que propiciam o reconhecimento de predicadores complexos com verbo suporte.

O elemento incorporado não é um termo pleno, ou seja, item ou expressão com a função de estabelecer referência, designar especificamente uma entidade do mundo biossocial. Sua significação é mais genérica. Sua função, na verdade, é especificar o evento geral (estado, processo, posição ou ação) expresso pelo verbo-suporte. Ocorre, tipicamente, em sua forma básica, ou seja, não é acompanhado de qualquer determinante (artigo, pronome) ou modificador (adjetivo, advérbio de intensidade), nem é flexionado em número. Ocupa, preferencialmente, a posição depois do verbo-suporte.

O não-atendimento a essas condições morfossintáticas para o elemento nãoverbal e para o verbo-suporte conduz à hesitação quanto ao grau de integração de $\mathrm{V}+\tilde{\mathrm{n}} \mathrm{V}$ num predicador complexo. (MACHADO VIEIRA, 2010, p.425)

“Trazer ao conhecimento" também possibilita tornar proeminente o papel de causador do participante sujeito: porém, de modo comparável a um predicador simples não cognato, como informar. É comparável também a outra construção de predicador verbal complexo, com slot para verbos causativos, como fazer/causar conhecer (em que o participante causado de conhecer é diferente do participante causador). Já em construtos anteriores (como "trazer uma solução"), o participante causador coincide com o participante causado do evento envolvido "solucionar" (Causador fazer/causar Causado solucionar), o que se manifesta em "Eu gostaria, porém, também de trazer minha opinião".

"Trazer de volta" soma-se aos predicadores complexos com potencial de tornar proeminente o papel do causador do participante sujeito, podendo ser associado a um predicador simples cognato ou não, como voltar (a) ou retomar. Opera, ainda, para sinalizar a noção de aspectualidade (retomada). Percebemos também que, assim como "trazer à discussão", em "trazer de volta" o participante sujeito promove o interlocutor ao papel de participante do evento.

No entanto, conforme o dado abaixo, a comparabilidade entre o predicado complexo analisado e o predicador simples nem sempre é possível: 
f) Então, o que queremos aqui é trazer esse conhecimento do dia a dia, trazer essa experiência, trazer esse tempo de serviço para que possa contar como critério de avaliação, permitindo assim a reserva de $20 \%$ no número de vagas nos concursos para delegado de polícia. (ALERJ, 20 de jun. de 2017)

No excerto acima, entendemos que, em "trazer esse conhecimento do dia a dia" e "trazer essa experiência", trazer mantém comportamento de predicador simples, em vista de não ser possível identificar um verbo pleno equivalente e de ele não formar um todo funcional com o elemento não-verbal que o acompanha. Neles, trazer tem comportamento de Vpredicador ao se compatibilizar a uma estrutura argumental de construção pessoal transitiva de movimento causado, comportamento diferente do que tem nos dados da construção verbonominal que constitui nosso objeto de estudo. Interessa a essa pesquisa mapear as diferentes configurações que o verbo trazer pode assumir ao ser atraído para um ou outro padrão construcional, bem como a relação de similaridade ou dissimilaridade dos predicadores que constitui com outros recursos de predicação, com outros predicadores (simples ou também complexos).

As construções de predicador com verbo suporte são expressões de natureza perifrástica que são morfossintaticamente equivalentes a verbos predicadores simples, ou também chamados de verbos plenos ${ }^{3}$. O verbo suporte, também denominado na literatura de verbo leve, verbo funcional, verbo operador, forma com um elemento não-verbal uma combinação cujo significado não está relacionado ao significado de cada constituinte. Assim, associamos à ocorrência "trazer uma solução" um significado (e não a cada uma de suas formas) que pode ser comparado ao do verbo pleno "solucionar" e que difere da soma dos significados "trazer + uma solução". Por isso, a unidade complexa não é composicional. Essa não-composicionalidade que a caracteriza não alcança, em todas as instanciações de construção de predicação com verbo suporte, o grau de opacidade semântica e o de integração sintática e conceptual envolvidos no predicado complexo reconhecido (nitidamente) como a chamada "expressão idiomática/cristalizada" (cf. MACHADO VIEIRA, 2014, que trata de graus de construcionalização lexical, ou ESTEVES, 2012, tese sobre (semi) lexicalização).

\footnotetext{
3 "Verbos plenos são aqueles que semanticamente têm significação lexical e sintaticamente ocupam o núcleo do predicado em um sintagma verbal” (BORBA, 1996 apud CHISHMAN, R. L. O; ABREU, D. T. B, 2014. p. 156).
} 
Nas expressões em foco neste artigo, podemos notar que o verbo suporte trazer, juntamente com um elemento não-verbal forma uma unidade funcional predicante, ou um predicador complexo. Esse elemento não-verbal é, em algumas leituras, comparado a objeto direto ou a oblíquo. Entende-se que ele, na verdade, não é um argumento, mas um elemento que se incorpora formal e funcionalmente ao verbo e com ele forma uma unidade verbal. Naturalmente, é possível, na triagem dos dados, esbarrarmos com instâncias de uso em que a incorporação/fusão do SN ou do SP a trazer é transparente e em que, então, tais instâncias se configuram como não-composicionais, ou com outros em que a incorporação/fusão é opaca ou relativamente opaca (casos de maior composicionalidade). Os dados abaixo exemplificam alguns casos de menor composicionalidade (mais cristalização formalfuncional):

g) “Sr. Deputado José Luiz Nanci, meu colega de bancada, é um prazer tê-lo presidindo o Expediente Inicial desta Sessão; Deputado Altineu Côrtes, Deputado Zaqueu; senhoras e senhores, venho à tribuna mais uma vez trazer à baila um tema que tem sido recorrente nas duas últimas semanas na grande imprensa brasileira, em função da orientação da Resolução $\mathrm{n}^{\mathrm{o}} 4$ do Conselho Nacional de Educação que trata da concepção da chamada "escola inclusiva", que trata do olhar pedagógico para o atendimento, através dos diversos sistemas de educação no país, para meninos que têm algum tipo de necessidade especial.” (ALERJ, 05 de abr. de 2011)

h) "Sr. Presidente, Srs. Deputados, Deputadas, servidores, imprensa, quero aproveitar esse espaço para trazer à tona a questão, ainda, da tragédia da Região Serrana e as preocupações da população que têm chegado até nós, no dia a dia nas ruas, através da internet e em alguns encontros, como o que aconteceu nesta segunda-feira próxima passada, no encontro com a Avit, Associação de Vítimas de Teresópolis." (ALERJ, 05 de out. de 2011)

Ao observarmos as expressões "trazer à baila" e "trazer à tona", podemos perceber que os elementos incorporados ao verbo (baila e tona) são semanticamente mais opacos e sintaticamente mais ligados; por isso, as expressões são configuradas como menos composicionais. Ou seja, tais expressões, em vista de sua menor composicionalidade, são mais cristalizadas (nos termos de MACHADO VIEIRA, 2014) que as expressões apresentadas anteriormente.

De acordo com Machado Vieira (2018), os predicadores complexos podem propiciar a codificação de um efeito semântico que não corresponde ao de uma forma verbal simples, independentemente de o verbo ser cognato ou não a um elemento não-verbal. 
É possível notar que as expressões acima funcionam como atenuadores do discurso, pois visam à preservação da face do indivíduo: o indivíduo busca, ao mesmo tempo, proteger sua própria face e respeitar a do outro. De acordo com Brown e Levinson (1978), a face é a "a auto-imagem pública que todo membro deseja reivindicar por si mesmo" (BROWN e LEVINSON, 1978, p. 61) ${ }^{4}$. Defendemos que as construções com verbo suporte trazer prestam-se ao intuito de configurar predicações em que se conceptualizam pragmaticamente a imagem do participante sujeito (que pode coincidir ou não com o papel de enunciador) para a abordagem social de um público-alvo/interlocutor ou da relação daquele participante com este, (i) de modo a promover um certo distanciamento de efeito(s) do estado de coisas que a predicação, em seu ato de fala situado no espaço da polêmica/do debate, representa e (ii) em benefício dessa imagem.

Concebemos que a construção de predicação com verbo suporte trazer integra o conjunto de mecanismos táticos ${ }^{5}$ de ação linguística que se relacionam a uma configuração discursiva que opera em prol de tornar eficaz e lograr uma intenção de comunicação. De acordo com Burgo (2012), a atenuação pode ser conceituada com base em procedimentos que visam a diminuir a força ilocutória do enunciado a fim de abrandar efeitos de sentido não convenientes aos interesses e propósitos do enunciador. A autora esclarece que os procedimentos de atenuação diferem dos marcadores de atenuação. Os procedimentos podem interferir e modificar o núcleo da unidade discursiva, como, por exemplo, as paráfrases atenuadoras. Já os marcadores demonstram fixidez formal e grande frequência de uso, além disso, devido a sua natureza formulaica, apresentam alto grau de convencionalidade.

Como compreendemos que a construção analisada corresponde a um importante recurso retórico determinado contextualmente, consideramos ser pertinente investigar o uso dos padrões construcionais dela oriundos registrado nos discursos de deputados da ALERJ, pois é possível identificar sua presença como estratégia para o convencimento e para a configuração do lugar sociodiscursivo do enunciador no imaginário coletivo.

Esta pesquisa fundamenta-se no quadro teórico da Linguística Funcional-Cognitiva e nos pressupostos da Gramática de Construções Baseada no Uso. Conforme Goldberg (1995,

\footnotetext{
4 “(...)the public self-image that every member wants to claim for himself (...)" (BROWN e LEVINSON, 1978, p. 61).

${ }^{5}$ Mecanismos táticos são as artes estratégicas de retórica do fazer linguístico na elaboração das relações interpessoais e/ou na organização do evento comunicativo.
} 
2006), Croft (2001), Givón (1995, 2001, 2005), Heine, Claudi e Hünnemeyer (1991) e Chafe (1994, 2018), a língua deve ser entendida como uma gramática que emerge do uso; deste modo, a inovação ou a mudança linguística é localizada na interação dos falantes e negociada entre falantes no curso da interação e numa comunidade (linguística ou de prática discursiva). Conforme a Gramática de Construções, uma rede de representações é formada por elos simbólicos e convencionais entre atributos de forma e função às quais indivíduos de uma comunidade chegam cognitivamente a partir das diversas experiências de uso ou processamento de uso nas quais se envolvem. Dessa forma, essa rede organiza-se com base em estabilização, variação e mudança de pareamentos forma-função/significado apreendidos via experiência.

Este artigo organiza-se em duas seções, além desta e da seção de considerações finais: na próxima seção, detalharemos nosso referencial teórico e informaremos escolhas metodológicas; depois, apresentaremos a construção formada com verbo trazer a partir dos dados coletados no site da ALERJ e, em seguida, projetaremos a rede de relações entre atributos de forma e função da construção de atenuação do discurso conforme o modelo de rede proposto por Diessel (2015).

\section{Aparato teórico-metodológico}

De acordo com o ponto de vista da Gramática de Construções, o que o falante precisa saber para produzir enunciados é um conjunto de representações (a partir da experiência em comunidade linguística) interconectadas. "A totalidade do nosso conhecimento da linguagem é capturada por uma rede de construções: 'um construct-i-con'” (GOLDBERG, 2003: 219).

O termo 'construção' é usado não somente em Gramática de Construções, mas também em diversas áreas da pesquisa linguística. Construção é definida como o pareamento entre forma e significado, que inclui palavras, expressões idiomáticas assim como padrões linguísticos frasais. Um padrão linguístico é reconhecido como uma construção desde que algum aspecto de sua forma ou função não seja previsível a partir de seus componentes ou de construções reconhecidas como existentes. 
Assim, de acordo com o ponto de vista cognitivo, todos os padrões gramaticais, tanto orais quanto frasais, são vistos como construções. Entendemos, portanto, que não há separação entre léxico e gramática, pois, conforme Diessel, "se a gramática consiste em sinais gramaticais, ou seja, construções, não há diferença de princípio entre gramática e léxico como em outras abordagens teóricas" (DIESSEL, 2015, p. 302).

Conforme Hilpert (2014), uma definição amplamente citada de construção foi fornecida por Goldberg (1995):

C é uma construção se e somente se $\mathrm{C}$ é um par forma-significado $<\mathrm{F}_{\mathrm{i}}, \mathrm{S}_{\mathrm{i}}>$, de tal forma que nenhum aspecto de $\mathrm{F}_{\mathrm{i}}$ ou de $\mathrm{S}_{\mathrm{i}}$ seja estritamente previsível a partir de partes componentes de $\mathrm{C}$ ou a partir de outras construções previamente estabelecidas. (GOLDBERG, 1995, p. 4, tradução nossa) ${ }^{6}$

Conforme a explicação de Hilpert (2014), a definição dada por Goldberg (1995) fornece três importantes noções. A primeira é que a construção combina uma forma linguística com um significado. A segunda é que uma construção é uma unidade de conhecimento, ou seja, não é uma forma que pode ser descrita sem que se faça uma referência ao conhecimento linguístico do falante, a uma representação mental. A terceira é que a definição fornece o critério de não previsibilidade. Assim, na relação forma-significado, um aspecto da forma ou do significado não é previsível.

Hilpert (2014) explica que o significado não composicional é a maneira mais fácil de identificar construções. Segundo o autor, construções não composicionais como "We're back to square one" (Estamos de volta à estaca zero) são não previsíveis. Hilpert esclarece que a definição não trata apenas de significados não previsíveis. Assim, segundo ele, as construções podem ser identificadas também com aspectos não previsíveis de sua forma. Ele cita que um tipo de sentença específica ou um esquema morfológico, como "all of a sudden" (de repente), "by and large" (em geral) é uma forma de construção não previsível, pois não são instâncias de um padrão formal mais geral.

\footnotetext{
${ }^{6} \mathrm{C}$ is a CONSTRUCTION iff $_{\text {def }} \mathrm{C}$ is a form-meaning pair $<\mathrm{F}_{\mathrm{i}}, \mathrm{S}_{\mathrm{i}}>$ such that some aspect of $\mathrm{F}_{\mathrm{i}}$ or some aspect of $\mathrm{S}_{\mathrm{i}}$ is not strictly predictable from C's component parts or from other previously established constructions. (GOLDBERG, 1995, p. 4)
} 
Hilpert (2014) salienta que atualmente os pesquisadores da Gramática de Construções não utilizam o critério de não previsibilidade para qualificar alguma expressão como construção. A razão disto é que há expressões que são semanticamente e estruturalmente transparentes, mas que parecem se qualificar como construções. O autor cita como exemplo as sentenças abaixo:
a) I love you. (Eu te amo.)
b) I don't know. (Eu não sei.)
c) Take a seat! (Sente-se!)
d) Can I ask you something? (Posso te perguntar uma coisa?)
e) How has your day been? (Como foi seu dia?)

Hilpert (2014) explica que a razão para ver as sentenças acima como construções é o fato de todas elas serem expressões muito frequentes e altamente convencionalizadas de dizer algo. O autor afirma que algumas expressões podem parecer expressões superficiais, mas que, devido ao uso repetido, tornaram-se a opção padrão em determinadas situações comunicativas.

De acordo com Hilpert (2014), Taylor (2012:100) oferece como exemplo a sentença “Quantos anos você tem?", que não tende a ser substituída por "Há quanto tempo você nasceu?" a fim de pedir a idade do interlocutor. Assim, Hilpert defende que esse tipo de informação deve estar presente no construct-i-con. Por esse motivo, ele afirma que Goldberg propôs uma nova definição de construção:

Qualquer padrão linguístico é reconhecido como uma construção, desde que algum aspecto de sua forma ou função não seja estritamente previsível a partir de suas partes componentes ou de outras construções reconhecidas como existentes. Além disso, os padrões são armazenados como construções, mesmo que sejam totalmente previsíveis, desde que ocorram com frequência suficiente. (GOLDBERG, 2006, p.5, tradução nossa) ${ }^{7}$

\footnotetext{
$7 \quad$ Any linguistic pattern is recognized as a construction as long as some aspect of its form or function is not strictly predictable from its component parts or from other constructions recognized to exist. In addition, patterns are stored as constructions even if they are fully predictable as long as they occur with sufficient frequency. (GOLDBERG, 2006, p. 5)
} 
Goldberg (2010) defende que, além do critério de não previsibilidade, os pares de formas e funções altamente frequentes também são reconhecidos como construções, mesmo quando composicionais. A autora acrescenta que, embora pareça que a adição de construções composicionais aumente desnecessariamente o tamanho da gramática, existem evidências de que as informações redundantes pertencem ao conhecimento linguístico.

Goldberg (2010) salienta que as sentenças raramente são compostas de uma única construção. De acordo com a autora, uma sentença normalmente envolve a combinação (unificação) de diferentes construções. Ela cita, como exemplo, a sentença "O esquilo quebrou sua noz" e afirma que, no exemplo, é possível identificar um sintagma verbal, um sintagma nominal, uma construção transitiva e uma construção de sujeito-predicado, assim como as construções individuais que correspondem a cada palavra da sentença (referidos, por DIESEL (2015), como lexemas).

Goldberg (2010) acrescenta que as construções podem ser combinadas livremente para formar expressões reais, desde que não haja conflitos. A autora cita que, na construção ditransitiva, na qual ocorre transferência de um remetente para um destinatário, existem restrições como em: "The man sent storage a Box" (O homem enviou (para o) armazenamento uma Caixa). Para a autora, não haveria restrições se a sentença fosse "The man sent a box to storage" (O homem enviou uma caixa para (o) armazenamento).

Goldberg (2010) advoga que as construções são motivadas por outras construções. Ou seja, generalizações amplas são representadas por construções que são herdadas por muitas outras construções. Assim, a construção 'What's X doing Y?' ('O que X está fazendo Y?') não é totalmente idiossincrática, pois herda propriedades de várias construções mais gerais, incluindo o isolamento esquerdo, a inversão sujeito-auxiliar, as construções de sujeitopredicado e de sintagma verbal.

Assim, é consenso na Gramática de Construções que, além de o conhecimento linguístico do falante ser um grande repositório de construções gramaticais e que essas estão interligadas em rede, existe uma exigência de compatibilidade gramatical para combinação de construções que leva à integração delas em um processo de formação de enunciados.

De acordo com a Gramática de Construções Baseada no Uso (GCBU), o uso afeta o conhecimento linguístico do falante. Assim, a totalidade do conhecimento linguístico do 
falante é construída a partir do input, ou seja, a experiência com o uso da língua molda continuamente o conhecimento internalizado do falante.

Além disso, a GCBU reconhece a possibilidade de representação redundante do conhecimento gramatical, portanto o compromisso dessa vertente é com a realidade psicológica e não com a economia descritiva. Assim, a GCBU se opõe às vertentes formalistas da Gramática de Construções, as quais se pautam na descrição econômica.

A partir dos pressupostos da Gramática de Construções Baseada no Uso, temos como objetivo realizar uma pesquisa qualitativa do uso de padrões construcionais licenciados por [trazerVsuporte

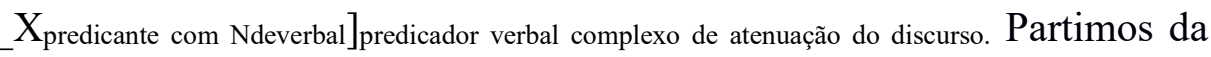
hipótese de que essa estrutura corresponde, no plano do conteúdo, à função de atenuação do discurso.

Utilizamos para esta pesquisa o banco de dados da Assembleia Legislativa do Rio de Janeiro (ALERJ). Os dados coletados correspondem a discursos apresentados entre os anos de 2011 e 2019 e estão disponibilizados no site eletrônico http://www.alerj.rj.gov.br, mais especificamente no ícone "Discursos". Para chegarmos a esse ícone, clicamos em "Processo legislativo", na página inicial do site. Logo em seguida, ao clicarmos em "Plenário", o site nos mostra a opção "Discursos", no qual fizemos a busca dos dados. Ao sermos direcionados a uma nova aba no site, digitamos a palavra trazer no item "Pesquisar" a fim de realizarmos a busca. Digitamos o verbo suporte trazer no infinitivo em vista de, em buscas anteriores, não termos localizado este verbo flexionado.

Em nossa pesquisa, observamos o grau de produtividade, de composicionalidade e de esquematicidade dos predicadores complexos com verbo suporte trazer. Segundo Traugott e Trousdale (2013), a produtividade está relacionada à frequência de uso e de tipo construcional. Quando são formadas novas microconstruções, há a potencialização gradual da frequência de uso, e não apenas da extensibilidade da construção em microconstruções. A noção de frequência, de acordo com Bybee (2003, 2006), compreende a frequência token e a frequência type. Esta corresponde à quantidade de diferentes expressões de um determinado padrão e aquela corresponde à extensão de uso de um determinado construto/uso. Utilizamos, portanto, em nossa análise, a palavra construto para nos referir às instanciações concretas da língua observadas nos textos consultados. A composicionalidade está relacionada ao grau de transparência entre forma e significado: quanto maior o acesso a um todo formal-funcional e 
menor o acesso aos componentes desse todo, menos composicional é a unidade, mais teor construcional esta tem; expressões idiomáticas/idiossincráticas, por exemplo, tendem a ser exemplares não-composicionais. E a esquematicidade é propriedade resultante de um processo de esquematização cognitiva ancorada em categorização, generalização e abstração a partir de input disponível na experiência de usos linguísticos, pois, quanto maior é a captura de padrões mais gerais e de atributos formais e funcionais para configuração dos slots destes padrões, maior é o grau de abstração na representação linguística.

\section{Análise de dados}

$\mathrm{Na}$ análise dos dados, trataremos, na primeira parte desta seção, de apresentar as instanciações de uso do padrão construcional licenciado por [trazervsuporte Elemento não-verbal predicante com Ndeverbal]predicador verbal complexo bem como a motivação pragmática dessas instanciações. Na segunda parte, trataremos da construção de atenuação do discurso interconectada em uma rede construcional por meio de links horizontais, taxonômicos, lexicais e sintáticos, conforme o modelo de rede proposto por Diessel (2015).

\section{O verbo suporte trazer e a construção de atenuação do discurso}

Neste trabalho, procuramos apresentar o padrão construcional licenciado por [TrazerVsuporte Elemento não-verbal predicante com Ndeverbal]predicador verbal complexo. Assim como Machado Vieira (2018), entendemos como verbo suporte os elementos verbais que formam com um elemento não-verbal (em geral um substantivo ou adjetivo) uma unidade funcional predicante, ou um predicador complexo.

A estrutura com verbo suporte trazer juntamente com elemento de natureza não-verbal constituído de Ndeverbal corresponde a um padrão linguístico que é representado no plano da forma, por [Trazer $\underline{\text { vsuporte }}+\mathrm{X}_{\text {predicante com Ndeverbal] }}$ predicador verbal complexo. Podemos perceber que tal estrutura constitui um esquema sintático semipreenchido. O slot para preenchimento de $\mathrm{X}_{\text {predicante com Ndeverbal }}$ pode conter, conforme os dados coletados abaixo, elementos como "uma denúncia”, "a solução", “a debate”, “à reflexão" etc. 
(1) "Mas a minha intenção em ocupar este expediente, Sr. Presidente, é para, também, trazer uma denúncia muito grave, porque, infelizmente, mostra a falência do Estado do Rio de Janeiro, em relação à responsabilidade que se tem na questão da segurança. Vejam, por exemplo, companheiros Deputados, os que estão me acompanhando pela TV Alerj, o que vou narrar aqui é uma situação que não dá para imaginar. Na Cidade de Deus, temos uma obra parada, há mais de dois anos, de uma escola que já consumiu milhões de reais, mas a construtora abandonou e, já há um bom tempo, o empenho do Secretário Wagner Victer, vê a necessidade de se oferecer o ensino médio para os estudantes da Região da Cidade de Deus, de Jacarepaguá, e a conclusão dessa obra." (ALERJ, 20/09/2018)

(2) "Diariamente, pais de família, trabalhadores, estão sendo vítimas desta obra federal que se encontra em total abandono. Hoje, ocupo o cargo de Deputada Estadual, mas nem por isso vou deixar de brigar pela população e de cobrar do Governo Federal as suas atribuições.

Protocolei, na Comissão de Obras Públicas, hoje, um pedido de audiência pública, para que possamos chamar a esta Casa os órgãos competentes para dar explicação. E, mais do que isso, trazer a solucão desse problema.” (ALERJ, 18/04/2019)

(3) "Em segundo lugar, quero trazer aqui um tema para reflexão, ligado à segurança pública, levantando o debate sobre a prevenção. Lembro quando estive no Ministério da Justiça e estimulei e defendi que tivéssemos aqui equipamentos tanto de proteção quanto para enfrentar a violência, equipamentos que pudessem permitir a atuação do profissional de segurança pública no sentido dele fazer o uso gradativo da força.

E quando se estuda esse assunto e procura fazer com que os profissionais da segurança pública possam fazer o uso gradativo da força, um dos temas que temos que trazer a debate é sobre as armas que muitos chamam de arma não letal, mas que na realidade são armas menos letais." (ALERJ, 21 de mar. de 2012)

(4) "Boa tarde todas e todos! Eu queria cumprimentar aqueles que me antecederam nesta tribuna, cumprimentar a nossa Presidente em exercício, Deputada Fatinha, e, de uma forma breve, queria trazer à reflexão alguns pontos.

O primeiro, partindo da premissa do gesto, ainda que singelo, feito no dia de hoje pela bancada feminina em razão da notícia de uma mulher que sofreu o assédio por parte de um ator de uma emissora famosa.

Eu quero dizer que, nas relações do assédio, é preciso destacar que de um lado eu tenho uma vítima que tem uma condição de subalterna em relação ao autor. Então, é essa a condição de superioridade do autor que impõe à vítima a prática de uma conduta para que ela seja mantida ou seja reconhecida no seu trabalho." (ALERJ, 06 de abr. de 2017)

Conforme os dados acima, percebemos que o elemento que segue o verbo suporte trazer é um sintagma nominal, como em (1) e (2), ou um sintagma preposicional, como em (3) e (4). Nos dados acima, identificamos que o verbo suporte trazer, em sua forma no 
infinitivo, apresenta algumas particularidades. Em (1), constitui uma estrutura clausal, iniciada com a preposição "para", que está inserida na sentença iniciada por "Mas a minha intenção em ocupar este expediente, Sr. Presidente, é...”.

Em (2), podemos perceber que a estrutura "trazer a solução" corresponde a uma cláusula que visa a retificar o conteúdo expresso na estrutura complexa "dar explicação" presente na sentença anterior. Assim, em "trazer a solução", percebemos que a preposição "para" está em elipse, pois corresponde a uma nova explicação que substitui a estrutura "dar explicação", que é iniciada com a preposição "para”.

Em (3), notamos que o verbo suporte trazer pertence a uma locução verbal (temos que trazer) e está inserido em uma cláusula relativa (que temos que trazer a debate). Em (4), também podemos observar que o verbo suporte trazer pertence a uma locução verbal (queria trazer). Em (3) e em (4), os elementos que seguem o verbo trazer são sintagmas preposicionais, no entanto, em (4), identificamos a presença de um objeto (alguns pontos) após o sintagma preposicional.

Ao analisarmos os construtos "trazer à discussão", "trazer de volta", "trazer à reflexão" e "trazer a debate", percebemos que o sintagma preposicional que segue o verbo trazer pode ser representado por "para/a + Ndeverbal" ou "de+ Ndeverbal". É possível notar que a estrutura denota a ideia de movimento, o que a aproxima da construção de movimento causado, cuja semântica básica definida como o argumento causador faz com que o argumento do tema se mova ao longo de um caminho e, conforme Goldberg $(1995,2006)$ é representada formalmente por "X CAUSES Y TO MOVE Z." Portanto, na análise dos dados, notamos que o movimento decorre do fato de o enunciador transferir ao interlocutor o papel de participante, permitindo-o que tenha contato com o tema a ser discutido.

A estrutura "trazer+sintagma nominal/sintagma preposicional" constitui, portanto, um padrão linguístico que, no plano da forma, apresenta esquema sintático semipreenchido e apresenta sequência fonológica. No plano do significado, percebemos que o padrão analisado apresenta informações de natureza pragmática. Entendemos que as construções "trazer uma denúncia", "trazer a solução", "trazer a debate" e "trazer à reflexão" equivalem semanticamente aos seus respectivos predicadores simples "denunciar", "solucionar", “debater' e "refletir", mas não são equivalentes pragmaticamente a tais predicadores simples. 
Entendemos que o que motiva o uso de construções com verbo suporte trazer é o fato de elas serem atenuadoras do discurso. Em (1), percebemos que o deputado busca diminuir a sua participação quanto à exposição da denúncia. "Fazer uma denúncia” ou "denunciar" são ações que possuem um efeito de sentido bastante intenso e, por isso, com o objetivo de amenizar essa conotação, vemos que o deputado utiliza a construção "trazer uma denúncia". Ele assume a imagem/o papel de porta-voz da denúncia de outro(s), por meio do acionamento dessa microconstrução.

Em (2), percebemos uma tentativa por parte do enunciador de tirar a responsabilidade da ação proposta. Seu papel foi de apenas protocolar um pedido de audiência pública e cabe não somente a ele, mas também aos órgãos competentes chegarem a uma solução para o problema.

Em (3), o deputado busca a primeira pessoa do plural com o objetivo de diluir o seu grau de participação. Vemos que há uma tentativa de convocação para um debate realizada pelo deputado, mas que essa convocação deve partir daqueles que compõem o conjunto de deputados na câmara. O papel dele é, portanto, o de lembrar quanto à importância do debate, o que configura uma diminuição da sua responsabilidade.

Em (4), também percebemos a estratégia de diminuir seu papel participativo, pois não cabe somente a ele a reflexão do tema, mas sim de todos que lá estão. Assim, "trazer à reflexão" constitui uma estratégia atenuadora que visa a amenizar o seu grau de participação.

Ao analisarmos os dados, podemos observar que a construção analisada apresenta quatro subesquemas, conforme a representação abaixo: 


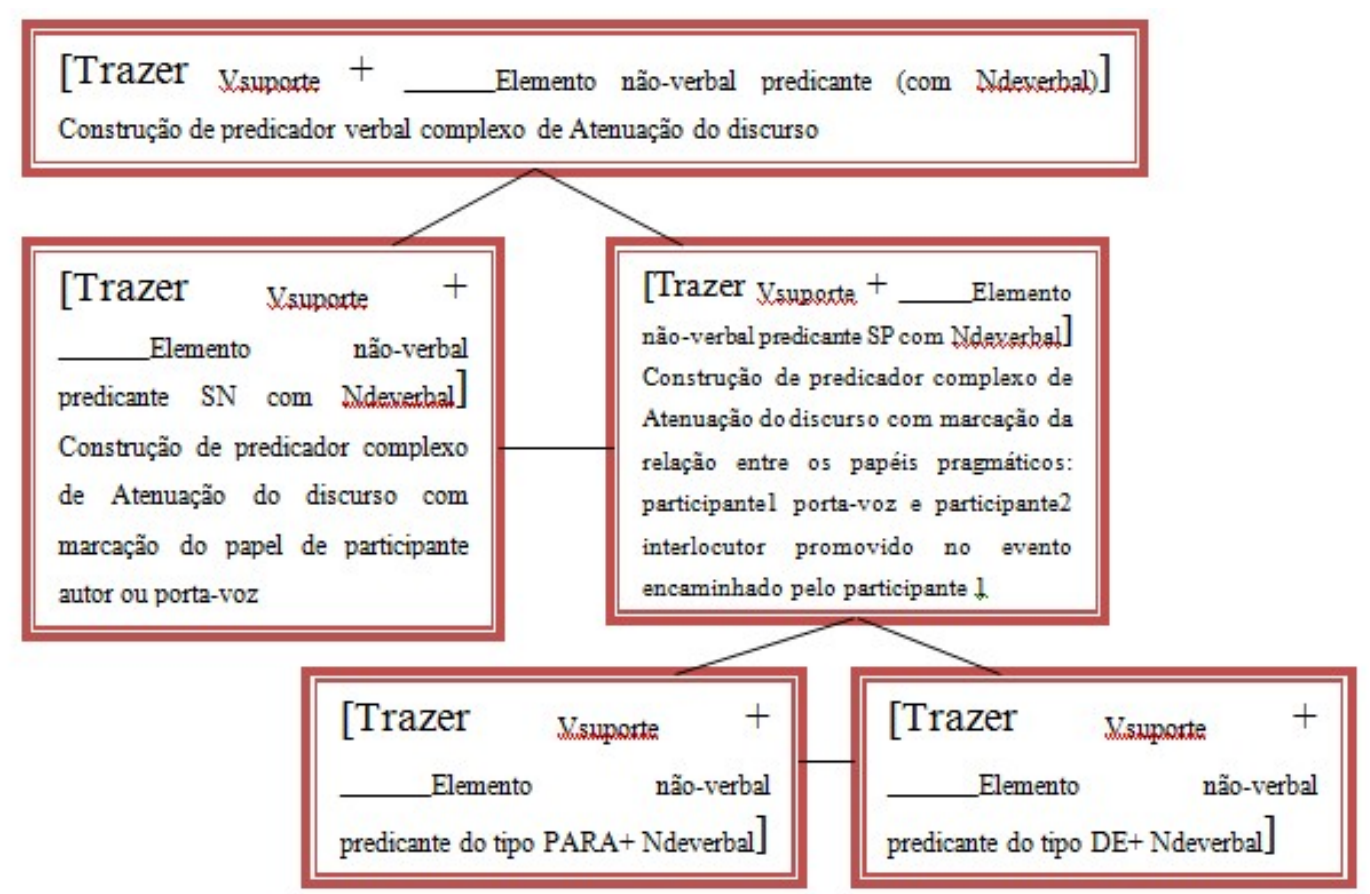

Figura 1 - Os subesquemas da construção de atenuação do discurso

Conforme a figura 1, a construção de predicador complexo de atenuação do discurso, cuja representação é [Trazer vsuporte + Elemento não-verbal predicante com Ndeverbal] predicador verbal complexo de atenuação, apresenta os subesquemas [Trazer vsuporte + Elemento não-verbal predicante SNcom Ndeverbal ] e [Trazer vsuporte + Elemento não-verbal predicante SPcom Ndeverbal]. O elemento deverbal pode ser preenchido por um sintagma nominal (SN) ou por um sintagma preposicional (SP). O primeiro viabiliza a tentativa de moldar um porta-voz, diminuindo o grau de participação do enunciador, dando-nos a impressão de que ele (o enunciador) não é o autor da denúncia apresentada ("trazer uma denúncia") ou o autor da solução proposta ("trazer a solução"). O segundo viabiliza uma relação intersubjetiva em que sobressai o papel do interlocutor na ação encaminhada pelo enunciador. Assim, cabe ao interlocutor se envolver na reflexão (trazer à reflexão), na discussão (trazer à discussão), no debate (trazer a debate) promovidos a partir do encaminhamento feito pelo enunciador. O segundo, por sua vez, licencia o preenchimento de SP por meio de duas configurações, ligadas, por relação de herança, a slots da configuração da construção de estrutura argumental de movimento causado: [Trazer vsuporte + Elemento nãoverbal predicante do tipo PARA+ Ndeverbal] e [Trazer Vsuporte + Elemento não-verbal predicante do tipo DE+ Ndeverbal]. Desses, o mais produtivo é o primeiro. 
Assim, advogamos que o padrão construcional licenciado por [Trazer vsuporte + Elemento não-verbal predicante com Ndeverbal] predicador verbal complexo de atenuação constitui uma construção independente em vista de não ser possível reconhecer nenhum aspecto de sua forma ou função a partir de outra construção. Portanto, trata-se de padrão único ou idiossincrático.

Além disso, a construção com verbo suporte trazer tem como função a atenuação do discurso, pois visa à preservação da face do falante. Galembeck (1999) afirma que não é possível prever as ações do interlocutor, assim o falante adota mecanismos que possam resguardá-lo de algo que não deseja ser exposto e que evidenciem aquilo que deseja ser exposto. De acordo com o autor:

A necessidade de preservação da face torna-se particularmente relevante em determinadas situações, nas quais o falante se expõe de forma direta: pedidos, atendimento de pedidos ou recusa em fazê-lo, perguntas diretas e indiretas, respostas, manifestações de opiniões. Cabe acrescentar que a preservação da face deve ser necessariamente considerada em relação ao quadro geral da interação, e não como uma atitude isolada do falante (GALEMBECK, 1999, p.174 apud BURGO, 2012, p. 46).

\section{A construção de atenuação do discurso e a rede construcional}

De acordo com o ponto de vista cognitivo, a gramática é uma rede de sinais interconectados, ou, conforme Langacker, um “inventário estruturado" de "unidades simbólicas" (LANGACKER 1987: 57). Segundo Diessel (2015), os modelos de rede têm uma longa tradição na ciência cognitiva. Existem diferentes modelos de rede, mas o que todos eles têm em comum é que são projetados para "processar" dados e "aprender" por meio da experiência com o processamento de dados. Os modelos de rede são, portanto, modelos baseados no uso. Diessel (2015) considera a existência de quatro tipos de links entre os elementos linguísticos. Assim, para entender a arquitetura da rede gramatical na abordagem baseada no uso, é importante entender como as unidades simbólicas, ou construções, estão inter-relacionadas.

Conforme Diessel (2015), o primeiro tipo de link diz respeito à organização hierárquica da gramática, em que construções mais esquemáticas da estrutura linguística 
instanciam construções concretas. Diessel (2015) argumenta que a relação entre construtos e construções é baseada em um processo de esquematização, como uma espécie de aprendizado implícito, conforme a figura abaixo:

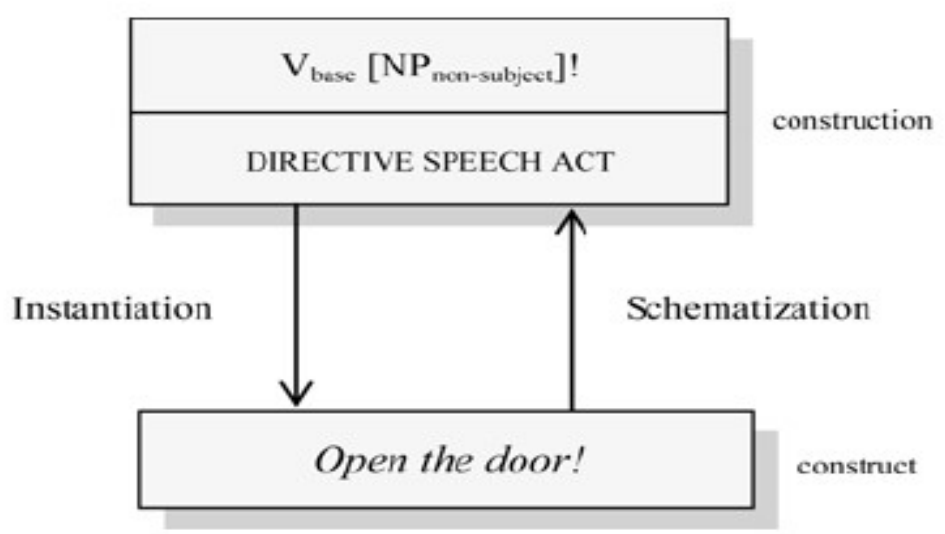

Figura 2 (DIESSEL, 2015, p. 303)

Na figura acima, o construto "Open the door!", em um nível abaixo da hierarquia construcional, está relacionado por meio de um processo de esquematização com a construção mais esquemática. Essa construção é representada, no plano da forma, por $\mathrm{V}_{\text {base }}[\mathrm{NP}$ non subject] e, no plano do significado, por "directive speech act" (ato de discurso diretivo) e, por meio de um processo de instanciação, licencia o uso do construto "Open the door!". Assim, o link que relaciona a construção e o construto é vertical e, por isso, é denominado por Diessel de link taxonômico.

Conforme observamos nos dados (1), (2), (3) e (4), as diferentes estruturas com verbo suporte trazer apresentam links taxonômicos com uma construção mais esquemática, conforme a representação abaixo: 


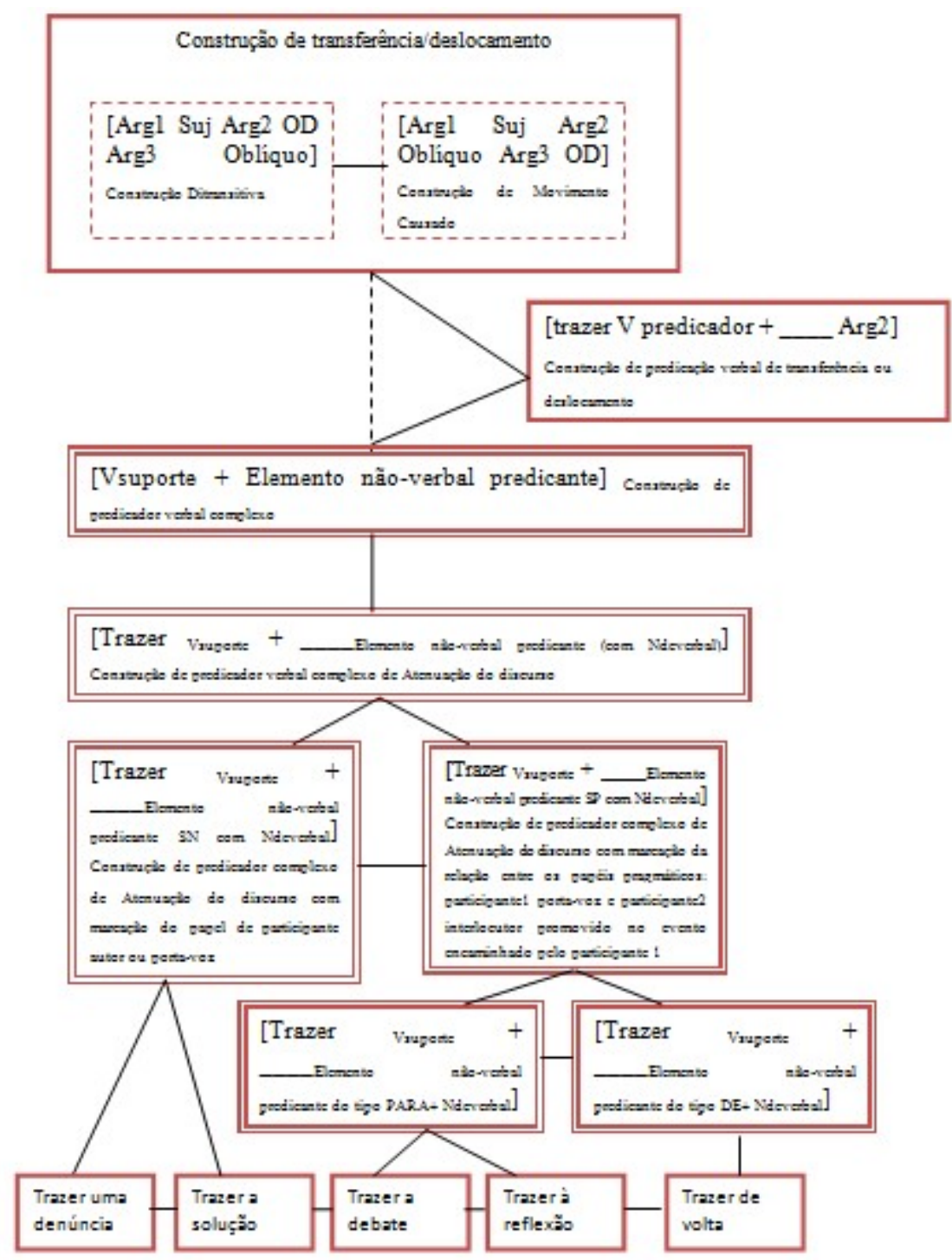

Figura 3 - Representação esquemática da construção de atenuação do discurso

Conforme a representação da figura 3, as expressões "trazer uma denúncia" e "trazer a solução" são instanciações da construção [Trazer vsuporte + Elemento não-verbal predicante SN com Ndeverbal], ao passo que as expressões "trazer a debate" e "trazer à reflexão" são instanciações da construção [Trazer Vsuporte + Elemento não-verbal predicante SP com Ndeverbal]. Ambas as construções são subesquemas da construção [Trazer vsuporte + Elemento não-verbal predicante] $]_{\text {predicador verbal }}$ complexo. Podemos observar que a construção [Trazer vsuporte + Elemento não-verbal predicante], juntamente com os subsesquemas, em vista de serem semipreenchidos, são mais esquemáticos que as expressões "trazer uma denúncia", "trazer a solução", "trazer a debate” e "trazer à 
reflexão", porém são menos esquemáticos que a construção [Trazer predicador + Arg2] Construção de predicação verbal de Transferência ou Deslocamento.

Entendemos que o preenchimento do slot da construção [Trazer vsuporte + Elemento não-verbal predicante deverbal] por um elemento deverbal aciona um outro tipo de predicação, em que o predicador se associa ao elemento deverbal e sobressai em trazer um estatuto de verbo suporte. Esse predicador é, portanto, diferente do estatuto de predicador que ele tem quando se liga a um argumento complemento objeto direto ou oblíquo.

O segundo tipo de link, conforme Diessel, diz respeito às relações entre construções ao mesmo nível de abstração. Esse tipo de link é denominado pelo autor de link horizontal. De acordo com Pinheiro (a sair), as associações entre construções em um mesmo nível de abstração ocorrem entre itens como "dia" e "noite", que, apesar de não terem semelhança formal, possuem relações semânticas. Além disso, o autor esclarece que a associação acontece com expressões fixas, como "pensar rápido" e "jogar fácil”, e padrões abstratos, como a Construção de Advérbio Canônico e a Construção de Adjetivo Adverbial.

$\mathrm{Na}$ figura 3, além da relação vertical ou taxonômica desde as expressões "trazer uma denúncia", "trazer a solução", "trazer a debate" e "trazer à reflexão" até a construção mais esquemática, podemos observar que há elementos relacionados por links horizontais. As expressões "trazer uma denúncia" e "trazer a solução" são licenciadas pela construção [Trazer Vsuporte + Elemento não-verbal predicante SN com Ndeverbal] e estão em uma mesma relação de horizontalidade com as expressões "trazer a debate" e "trazer à reflexão", licenciadas pela construção [Trazer Vsuporte + Elemento não-verbal predicante SP]. Ambas as construções semipreenchidas estão também ligadas horizontalmente, pois constituem dois subesquemas da construção [Trazer vsuporte + Elemento não-verbal predicante deverbal].

O terceiro tipo de link, conforme Diessel (2015), diz respeito à relação entre construções e categorias sintáticas, como relações gramaticais (sujeito, objeto etc.) e classes de palavras (substantivo, verbo etc.). De acordo com o autor, a maioria das teorias gramaticais define as categorias sintáticas em um nível muito alto de abstração. Tais abordagens incluem um inventário universal de categorias altamente esquemáticas definidas antes da análise sintática.

Em contraposição a maior parte das abordagens linguísticas, Croft (2001) oferece uma alternativa em que as categorias sintáticas são emergentes das construções. Assim, segundo 
Croft, "Construções, não categorias e relações, são as unidades básicas e primitivas da representação sintática" (Croft, 2001, p.45-46). Conforme Croft, as construções são as unidades básicas da gramática, porque, ao contrário do que normalmente se assume na teoria linguística, as configurações sintáticas não são deriváveis dos primitivos indivisíveis. Para ele, as categorias sintáticas são formadas no processo de aquisição e mudança linguística, portanto, são emergentes da análise inconsciente do usuário da língua e estão sujeitas a alterações.

De acordo com Diessel (2015), a relação entre construções e categorias é semelhante à relação entre construções em diferentes níveis de abstração. Enquanto as construções são generalizações sobre expressões concretas, os construtos e categorias são generalizações sobre partes recorrentes das construções. Segundo o autor, a partir dessa comparação, podemos pensar em relações gramaticais e classes de palavras como categorias emergentes da estrutura linguística que são ajustadas e reforçadas continuamente. Deste modo, assim como os construtos e as construções, as categorias e as construções são relacionadas entre si por meio de links taxonômicos que fazem parte do nosso conhecimento gramatical.

$\mathrm{Na}$ figura abaixo, podemos observar o link sintático inter-relacionando as construções com verbo suporte trazer:

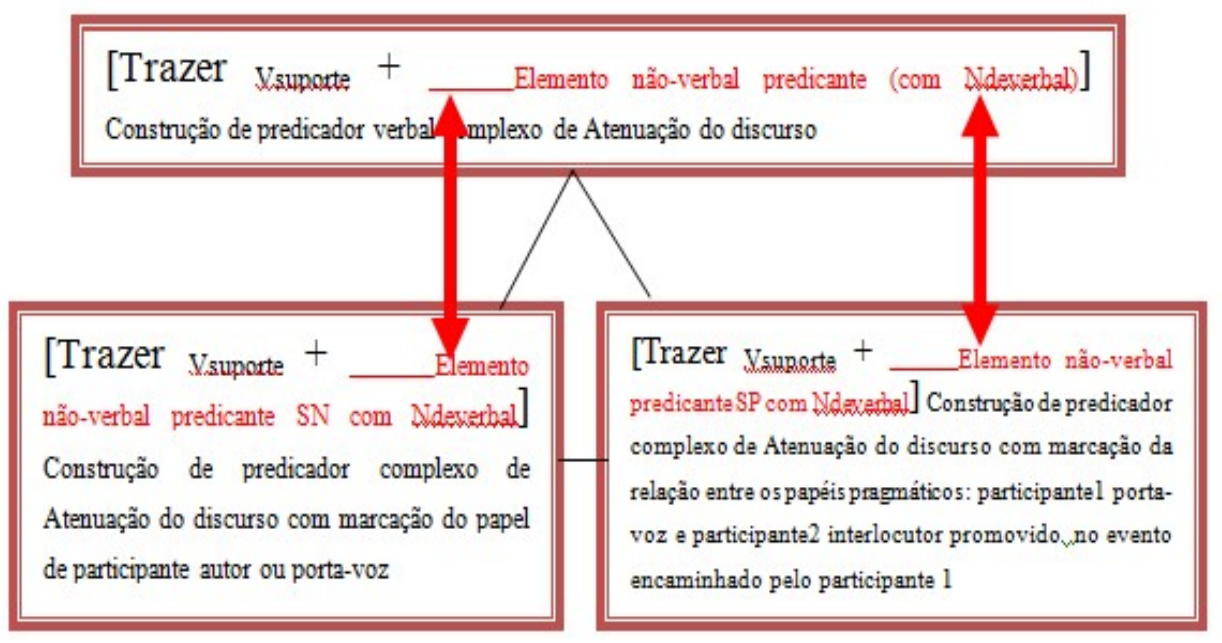

Figura 4 - A inter-relação entre as construções com verbo suporte trazer e as categorias gramaticais 
$\mathrm{Na}$ figura acima, podemos ver que o link taxonômico interconecta categorias gramaticais. Na construção mais esquemática, a categoria “ Elemento não-verbal predicante (com Ndeverbal)" licencia o uso das categorias “ Elemento não-verbal predicante SN com Ndeverbal" e “ Elemento não-verbal predicante SP com Ndeverbal", que compõem as instâncias menos esquemáticas. Denominamos o elemento associado ao verbo trazer de elemento não-verbal predicante, devido a esse apresentar propriedade de verbalidade envolvidade/eventividade ou situacionalidade, que é uma característica de verbos ou predicadores verbais. Esse elemento que preenche o slot ligado ao verbo trazer não é, portanto, um argumento, ou seja, não se trata de um objeto do verbo. Assim, conforme demonstramos na figura 3, entendemos que as categorias sintáticas são configuradas como generalizações sobre partes da construção. E, assim como Croft, entendemos as construções como unidades básicas da representação sintática.

Diessel (2015) também defende a existência de links associativos entre construções (esquemáticas) e expressões lexicais (concretas). O autor acrescenta que, ao contrário da abordagem estruturalista e gerativista, em que as palavras individuais são irrelevantes para a análise gramatical, a abordagem baseada no uso defende que a estrutura linguística fundamenta-se na experiência do usuário da língua com expressões lexicais concretas.

Conforme Diessel (2015), Stefanowitsch e Gries (2003) desenvolveram uma análise coloconstrucional a fim de analisar as ligações probabilísticas entre lexemas e construções. Para ilustrar a análise, o autor apresenta a construção ditransitiva, que consiste em um sujeito, um verbo e dois elementos nominais e que denota um ato de transferência entre um remetente e um destinatário. Os autores demonstraram que lexemas individuais são mais frequentes em uma construção específica do que estatisticamente esperado, se as relações entre lexemas e construções fossem aleatórias. Assim, o verbo give (“dar”) é fortemente associado à Construção ditransitiva e pouco frequente em construções com verbo dativo. Já o verbo bring ("trazer") é o contrário, ou seja, mais associado à construção com verbo dativo do que com a construção ditransitiva, conforme a figura abaixo: 


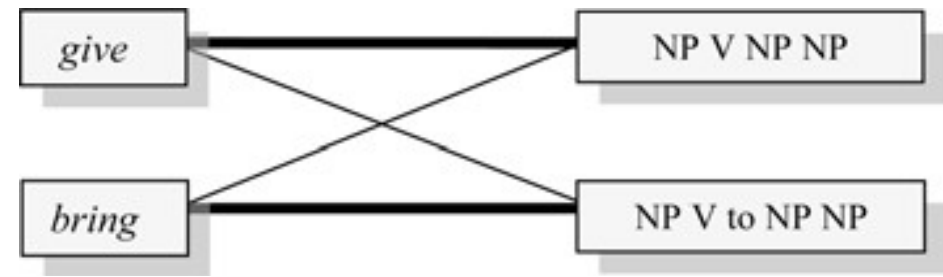

Figura 5 (DIESSEL, 2015, p. 313)

Conforme Diessel (2015), tanto a construção ditransitiva quanto a construção dativa denotam ato de transferência, mas apresentam diferenças sutis de significado. Na construção dativa, há maior distância entre o remetente e o destinatário e, assim, a construção dativa está mais associada a atividades que envolvem movimento. Essa explicação, segundo o autor, permite-nos entender o motivo de os verbos "trazer" e "levar" serem mais frequentes em construções dativas. Já os verbos "dar" e "contar" são mais frequentes na construção ditransitiva. É possível concluir que há uma tendência a usar verbos que são compatíveis com o significado construtivo. Essa compatibilidade é denominada por Goldberg (1995:50) de "Princípio da coerência semântica".

Segundo Diessel (2015), é possível pensar na relação entre lexemas e construções como parte de uma rede probabilística modelada pelo uso da linguagem. Assim, os verbos e outros lexemas e as construções são relacionadas entre si por conexões que resultam da experiência linguística do falante com expressões e construções lexicais específicas.

Conforme os dados que apresentamos em (1), (2), (3) e (4), foi possível identificar elementos lexicais (denúncia, solução, debate, reflexão) fortemente associados à Construção que denota Atenuação do discurso. Em vista dessa associação entre tais elementos e a construção mais esquemática, podemos afirmar que esses estão em um mesmo nível da hierarquia construcional e estão conectados por meio de links lexicais, conforme a figura abaixo: 


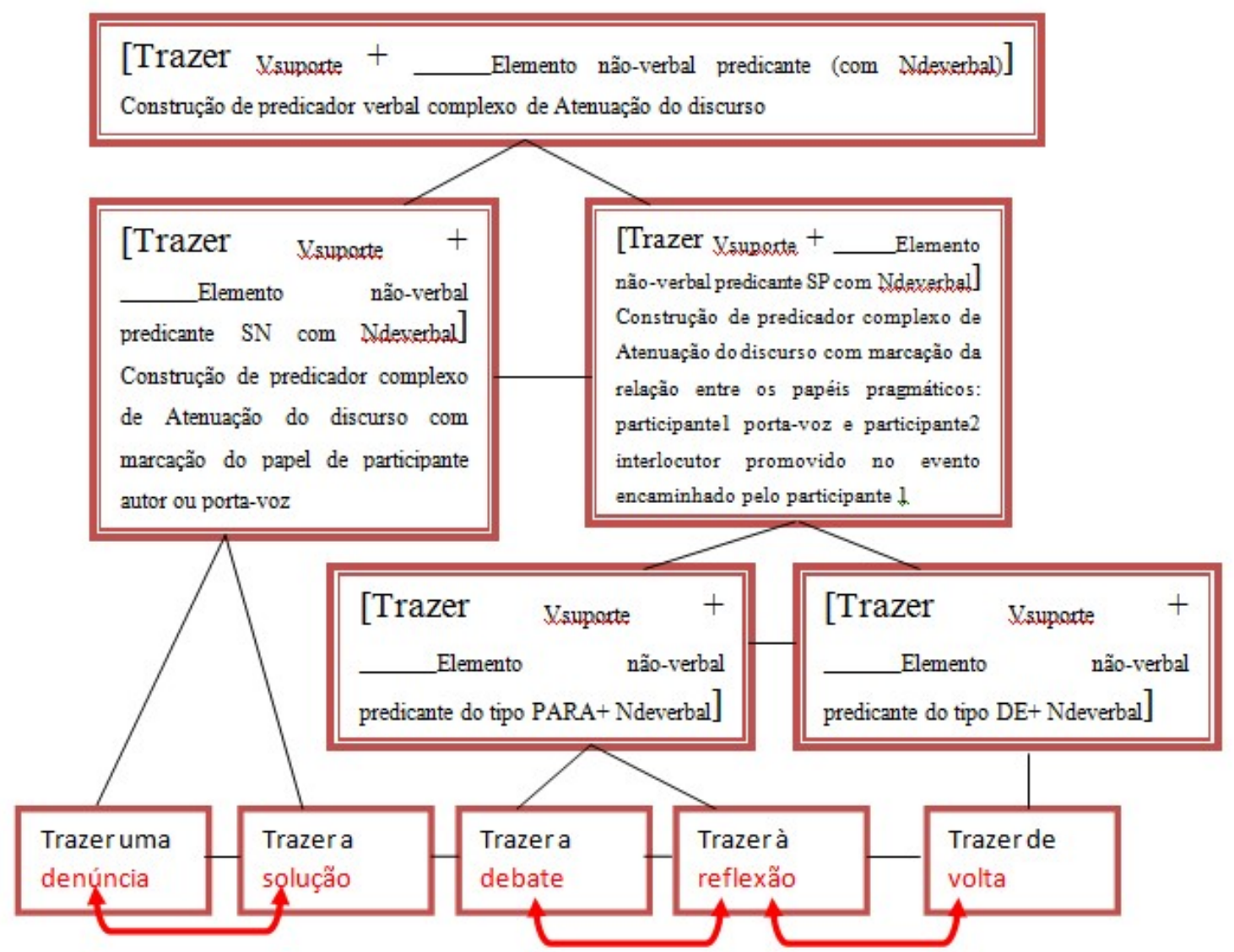

Figura 6 - A inter-relação entre as construções com verbo suporte trazer e os elementos lexicais

Conforme a figura acima, os elementos lexicais "denúncia" e "solução" são compatíveis a preencherem o slot de sintagma nominal e, portanto, estão conectados por link lexical. Da mesma forma, os elementos lexicais "debate", "reflexão" e "volta" estão conectados por serem compatíveis a preencherem o slot de sintagma preposicional. Podemos dizer que tais elementos lexicais estão em um mesmo nível de hierarquia construcional em vista de serem elementos deverbais predicantes e por serem compatíveis a preencherem o slot X com Ndeverbal na construção de atenuação do discurso.

\section{Considerações finais}

No presente trabalho, foi possível observar os diferentes usos da construção formada com verbo suporte trazer, tais como "trazer uma denúncia", "trazer a solução", "trazer a 
debate", "trazer à reflexão" etc. Tais usos constituem-se como instanciações da Construção de atenuação do discurso que, no plano da forma, é representada por [trazer $\underline{\text { vsuporte }}{ }^{+}$

Elemento não-verbal predicante com Ndeverbal ] predicador verbal complexo.

A partir da observação dos dados, foi possível constatar que o papel de causador do participante sujeito da construção de predicação verbal complexa pode coincidir com o da predicação simples, como em "trazer uma denúncia"/“denunciar" ou "trazer uma opinião"/“opinar". Ou, então, o papel de causador do participante sujeito pode coincidir com outra construção de predicação verbal complexa, como em "trazer ao conhecimento"/ "fazer conhecer".

Observamos também que, quando o elemento deverbal é preenchido com sintagma nominal (SN), é realçado o encaminhamento feito pelo enunciador, como em "trazer uma denúncia" e "trazer a solução". Ao passo que, quando o elemento deverbal é preenchido com sintagma preposicional (SP), o interlocutor é promovido à participante do evento, como em “trazer à reflexão" e "trazer à discussão".

Conforme o modelo de rede proposto por Diessel (2015), identificamos que as instanciações com verbo suporte trazer estão interconectadas por meio de links horizontais. Deste modo, as construções [Trazer vsuporte + __Elemento não-verbal predicante com Ndeverbal SN] e [Trazer Vsuporte ${ }^{+}$__Elemento não-verbal predicante SP] estão conectadas horizontalmente, pois constituem dois subesquemas da construção de atenuação do discurso, e instanciam respectivamente as construções "trazer uma denúncia"/“trazer a solução" e "trazer a debate"/“trazer à reflexão". Tais construções estão, portanto, em um mesmo nível hierárquico.

Além disso, os dois subesquemas estão conectados por link taxonômico à construção de atenuação do discurso. Esta última, por sua vez, está conectada também por link taxonômico à construção mais esquemática, representada formalmente como [Trazer predicador + Arg2] e funcionalmente como Construção de predicação verbal de Transferência ou Deslocamento.

De acordo com o modelo de rede apresentado por Diessel (2015), além do link taxonômico e do link horizontal, pudemos identificar que as construções estão conectadas por links sintáticos, que inter-relacionam as construções e as categorias sintáticas, conforme observamos entre [___ Arg2] e [___Elemento não-verbal predicante com Ndeverbal]. Assim, conforme Croft, entendemos que as categorias sintáticas são emergentes das construções, pois essas, não 


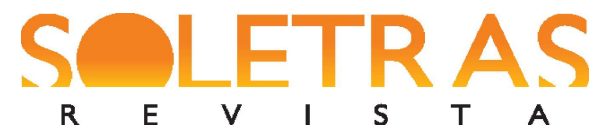

N. 41 - 2021.1 - FÁBIO RODRIGO GOMES DA COSTA

MARCIA DOS SANTOS MACHADO VIEIRA

aquelas, são as unidades básicas e primitivas da representação gramatical. Também reconhecemos a presença do link lexical que interconecta os elementos compatíveis a preencherem o slot [__ X com Ndeverbal].

\section{Referências}

BROWN, P.; LEVINSON, S. C. Politeness: some universals in language usage. $2^{\mathrm{a}}$ ed. Cambridge: Cambridge University Press, 1987.

BURGO, V. H. Efeitos de atenuação no discurso político: polidez e preservação da face na interação verbal. Revista Investigações, vol. 25, número 2, 2012.

CHAFE, W. Discourse, consciousness and time. The flow and displacement of conscious experience in peaking and writing. Chicago: The University of Chicago Press, 1994.

. Thought-based linguistics. How languages turn thoughts into sounds. Cambridge: Cambridge University Press, 2018.

CHISHMAN, R. L. O; ABREU, D. T. B. Construções com verbos-suporte: propriedades gramaticais e discursivas. Linha D'Água (Online), São Paulo, v. 27, n. 1, p. 153-168, jun. 2014

CROFT, W. Radical Construction Grammar. Oxford: Oxford University Press, 2001.

DIESSEL, H. Usage-based Construction Grammar. In: DABROWSKA, E.; DIVJAK, D. The Handbook of Cognitive Linguistics. Berlin / New York: Mouton de Gruyter, 2015.

ESTEVES, G. A. T. A lexicalização de expressões DAR/FAZER + SN: fiz sacrificio, dei conta. Tese de Doutorado. Universidade Federal do Rio de Janeiro: Faculdade de Letras, 2012.

GALEMBECK, P. de T. Preservação da face e manifestação de opiniões: um caso de jogo duplo. In: PRETI, D. (Org.) O discurso oral culto. $2^{\mathrm{a}}$ ed. São Paulo: Humanitas/FFLCH/USP Projetos Paralelos, vol. 2, p. 173-194, 1999.

GIVÓN, T. Functionalism and grammar. Amsterdam: John Benjamins, 1995.

.Context as other minds - the pragmatics of sociality, cognition and communication. Amsterdam: John Benjamins, 2005.

. Syntax. v. I. Amsterdam: John Benjamins, 2001. 


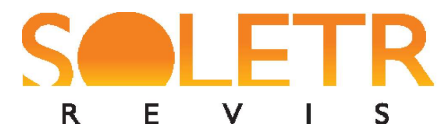

N. 41 - 2021.1 - FÁBIO RODRIGO GOMES DA COSTA

MARCIA DOS SANTOS MACHADO VIEIRA

GOLDBERG, A. E.; SUTTLE, L. Construction grammar. WIREs Cognitive Science, 1, 4, p. 468-477, 2010.

GOLDBERG, A. E. Constructions at Work: The Nature of Generalization in Language, Oxford: Oxford University Press, 2006.

Constructions: A new theoretical approach to language, Trends in Cognitive Sciences 7/5:219-24, 2003.

. Construction. A construction grammar approach to argument structure. Chicago: The University of Chicago Press, 1995.

HEINE, B.; CLAUDI, U.; HÜNNEMEYER, F. Grammaticalization: a conceptual framework. Chicago: The University of Chicago Press, 1991.

HILPERT, M. Construction grammar and its aplication to English. Edinburgh: Edinburgh University Press, 2014.

LANGACKER, R. W. Foundations of Cognitive Grammar: theoretical prerequisites, v. 1. Standford University Press, 1987.

MACHADO VIEIRA, M. dos S. Predicar com construção com verbo suporte. In: DE PAULA et al. (Org.) Uma História de Investigações sobre a Língua Portuguesa: Homenagem a Silvia Brandão. São Paulo: Blucher, 2018. p. 91 -112.

. Idiomaticidade em construções com verbo suporte do Português. SOLETRAS online, n.28, 2014. p. 99-125.

. Perífrases verbo-nominais. Estudos Linguísticos/Linguistic Studies, 5, Edições Colibri/CLUNL, Lisboa, 2010, p. 409-430.

PINHEIRO, D. Sintaxe Construcionista. In: OTHERO, G. A.; KENEDY, E. (Org.). Sintaxe, sintaxes: uma introdução. São Paulo: Contexto, 2015.

Um modelo gramatical para a linguística funcional-cognitiva: da Gramática de Construções para a Gramática de Construções Baseada no Uso. In: ALVARO, P. T..; FERRARI, L. (Orgs.). Linguística Cognitiva: dos bastidores da cognição à linguagem. Campos: Brasil Multicultural, a sair.

TRAUGOTT, E. C. \& TROUSDALE, G. Constructionalization and Constructional Changes. Oxford: Oxford University Press, 2013. 


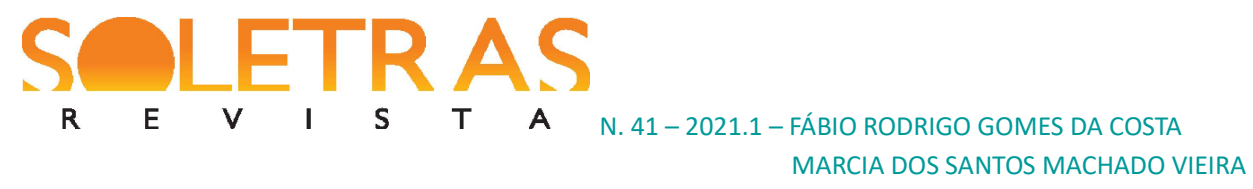

\title{
The construction of speech attenuation with support verb trazer (to bring): a constructional approach based on the use
}

\begin{abstract}
This article aims to analyze the construction of speech attenuation, which, in terms of form, is represented by the structure [trazervsupport + Predictive non-verbal element (with Ndeverbal) $]_{\text {complex verbal predicator. }}$. This construction licenses constructional subschemes that either involve NP with deverbalN or PP with deverbalN in the second slot, intended for a non-verbal predicative element. The construction and its constructional subschemes are interconnected in a constructional network through taxonomic, horizontal, syntactic and lexical links, according to the network model proposed by Diessel (2015). The observed expressions, collected in the database of the website of the Legislative Assembly of Rio de Janeiro (ALERJ), were identified in speeches of deputies between the years 2011 and 2019. The theoretical and methodological apparatus of this analysis is the Functional-Cognitive Linguistics and the Usage-Based Construction Grammar (UBCG). From the data analysis, these results stand out: (i) the filling of non-verbal element by NP with deverbalN makes it possible to shape the subject participant (which may or may not coincide with the speaker) in the figure of a spokesperson and (ii) its completion by PP with deverbalN makes it possible to highlight the role of the interlocutor in the state-of-affairs forwarded by the speaker.
\end{abstract}

Keywords: Support verb construction; Speech attenuation; Usage-Based Construction Grammar; Functional-Cognitive Linguistics.

Recebido em: 03 de novembro de 2020.

Aceito em: 17 de dezembro de 2020. 